\title{
Properties of Color Images Pictured on Sunlight and Different Wave Lengths
}

\author{
Zaid Mohammed \\ Baghdad College of Pharmacy \\ Iraq/ Baghdad \\ Baghdad/Bab_almuadum
}

\begin{abstract}
That the amount of the clarity in the color attribute in the single-image depends on the intensity of illumination, as well as the type of light used and the angle of its fall .This research we adopted in the light of the sun and different intensities on throughout the day and the angle of light on the picture, the purpose of Study changes in the color information received from camera. The proposed methods to address these data to get the clearest picture, It was also we working to shed different wavelengths between 400 to $750 \mathrm{~nm}$ and the wavelength of $255 \mathrm{~nm}$ and $366 \mathrm{~nm}$ for the purpose of studying the characteristics of the image. And we can looking for the disappearance of some band of color (RGB) colorimetric with small Concentration and its appearance at other times due to changes in the angle and intensity of light on the image, so the color shows the characteristic change color in the picture and the emergence of a difference in the captured image with time. The adoption of the mediator and the rate calculated the amount of the standard deviation of the color band in all the captured images. In order to find out which color packets disappear or appear based on light intensity, It was also we deducted three areas of each color of the primary colors in the image ( red, Green, blue) and calculate the amount of the standard deviation for it to know the times that appear or disappear some of the color packets .
\end{abstract}

\section{General Terms}

The general terms we used general classification of image analysis by different time taken image for get better depend on the sources light.

\section{Keywords}

Exposure of camera, sun light, mean of image, measure of image quality.

\section{INTRODUCTION}

Digital image processing is a subfield of digital signal processing. Digital image processing has many advantages over analog image processing; it allows a much wider range of algorithms to be applied to the input data and can avoid problems such as the build-up of noise and signal distortion during processing[1]. The captured images typically have low signal-to-noise ratio, and the demosaicing step further corrupts the image, [2]. In most digital images, pixel values aren't proportional to the light levels in the scene. Usually, light levels are encoded nonlinearly so they appear either more correctly or more pleasingly on nonlinear display devices such as cathode ray tubes. Furthermore, standard digital images typically represent only a small fraction of the dynamic range - the ratio between the dimmest and brightest regions accurately represented-present in most real world lighting environments. When part of a scene is too bright, the pixels saturate to their maximum value (usually 255) no matter how bright they really are. [3]. We can optically modulate the colors of a real-world scene so that visible differences are preserved for people suffering from color blindness [4].

\section{Measurements of image filter}

Photos comprise rich and well-structured visual information. In human visual perception, edges are effective and expressive stimulation, vital for neural interpretation to make the best sense of the scene. In manipulating and understanding pictures, high-level inference with regard to salient structures it was intensively [5]. There are many filters for Digital Image Smoothing, which could directly apply to enhance the noisy images.

a) Minimum filter

The minimum-filter selects the smallest value within the ordered of smoothing window of pixel values.

b) Mean filter

The mean filter technique operates by reducing the statistical fluctuations in each pixel by averaging the pixel with its closest neighbors. Mean-filter can be implemented directly to replace the image pixel values $I(i, j)$ by their mean values $\hat{I}(i, j)$, over sliding window.

c) Median filter

This filter replaces the gray level of each pixel by the median of the gray levels in a neighborhood of that pixel. Recall that the median $\mathrm{M}$ of a set of values is such that half of the values in the set are less than $\mathrm{M}$ and half are greater than $\mathrm{M}$. In order to perform median filtering in a neighborhood of a pixel must be sort the values of the pixel and its neighbors, then determine the median, and assign this value to the pixel [6].

d) Mode filters:

Mode-filter is another example of the smoothing filters in which the window's central pixel value is replaced by the point's value of the greatest repeated in the sliding mask. The mode filter is defined in the same way as the median filter, but instead of taking the median of the pixels in a neighborhood, that take the value of highest repetition in the sliding mask.[6]

\section{Statistical of images}

To measure the quality of the results images that has been obtained by applying enhancement techniques the following measurements can be adopted.

- Mean and variance

The mean $(\mu)$ of a set of values is it's statistical average, such that, if I represents a set of $\mathrm{N}$ values the mean can be written as[5]:

$$
\mu=\frac{1}{N} \sum_{i=1}^{N} I_{i}
$$

The mean of a set of values locates only the average value. It is helpful to know how much the data varies from its mean. The variance $V^{2}$ of a random variable I with expected value $\mu$ is given by[6]: 


$$
\mathrm{v}^{2}=\frac{\sum_{\mathrm{i}=1}^{\mathrm{N}}\left(\mathrm{I}_{\mathrm{i}}-\mu\right)}{\mathrm{N}-1}
$$

The smallest value of $\mathrm{V}^{2}$ can be assumed is zero, and that would occur if all the I-samples take the same value. The variation between the samples increase, the variance will be increased.

Since the variance is expressed in square units, more useful value is the square root of the variance, which is expressed in units, and can be related back to the original values. The standard deviation (STD) of a random variable I is the square root of the variance as follows[6]:

$$
\mathrm{STD}=\sqrt{\frac{\sum_{\mathrm{i}=1}^{\mathrm{N}}\left(\mathrm{I}_{\mathrm{i}}-\mu\right)}{\mathrm{N}-1}}
$$

\section{Some of system analyses}

\section{TLC Scanner 4 works :}

The signal of the measuring photomultiplier is continuously offset against the signal of the reference photomultiplier. This compensates for lamp aging and short-time fluctuations. It also reduces the warm-up time required to reach lamp stabilization. All components of the optical system, lamps, monochromator, scanning stage, and photomultiplier are mounted on one sturdy metal support. This ensures high precision of the detector signal. For scanning at wavelengths below $200 \mathrm{~nm}$ it is advisable to flush the monochromator with nitrogen. The scanner is equipped to do this.A monochromator bandwidth of $5 \mathrm{~nm}$ or $20 \mathrm{~nm}$ can be selected. $5 \mathrm{~nm}$ bandwidth is used for spectra recording, multiwavelength scanning, and when spectral selectivity is required. $20 \mathrm{~nm}$ bandwidth offers higher light intensity (improves the signalto-noise ratio and thus the reproducibility of the measurement) and enables measurement of several fractions with slightly different absorption maxima in one scan. The lens system with $190-900 \mathrm{~nm}$ transmission range features automatic positioning for micro and macro slit sizes. This ensures that the light energy available with small slits in the micro position is almost the same as that for the corresponding slit in the macro position, which is four times larger. The light beam strikes the object at right angle. The photomultiplier is aligned at an angle of $30^{\circ}$

\section{TLC Visualizer:}

TlC visualizer captures images that are, without a doubt, of the best quality in the field. The system provides illumination with direct and/or transmitted white light as well as with direct UV $254 \mathrm{~nm}$ and UV $366 \mathrm{~nm}$ light. An integrated powerful 12 bit camera with highly linear CCD chip and excellent color reproduction captures the images with the whole process conveniently controlled by the TLC software.[7] See the Fig.1 .

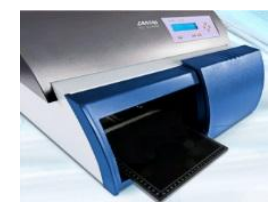

TLCScanner4

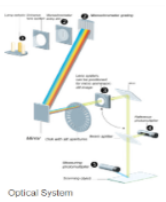

TLC Visualizer

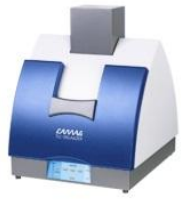

Fig.1 for TLC scanner4 and TLC Visualizer capture image

\section{The method and work and results}

In the system of work, the Image was developed towards the north and Camera has been developed to the south, we take a picture every half hour. See the Fig. 2 shows the system work location.

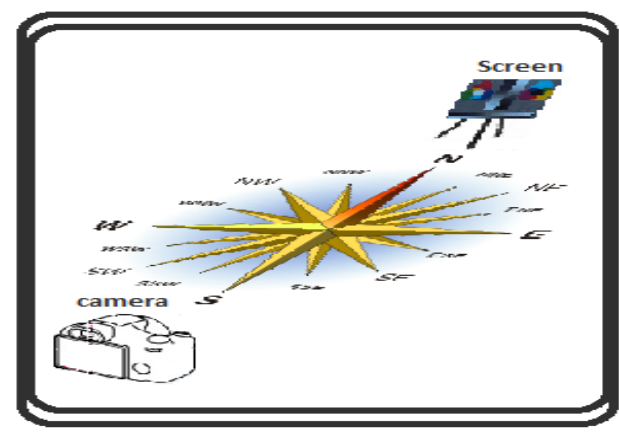

Fig. 2 system work location

\section{Image test results}

To study the difference between images taken at different times in the day with in a different light intensity depend on sunlight, so that we calculated statistical characteristics of the mean and standard deviation of RGB of intensity of each image .And shows the relationship between the average $(\mu)$ and standard deviation $(\sigma)$. When the distance between photo and camera the fixed.

A. The first part in this project we numerate the image from 1 to 23, which represents the capture image from six o'clock in the morning to six pm and calculate the standard deviation for it. And use the median rate filter to improve the image and calculate the standard deviation after improve mean filter, We can see the original image in Fig. 3 , and the histogram of the original image ,see the Fig.4 ,also gave the properties of the all image in (RGB) by calculated (STD\& $\sigma$ ) see the table. 1

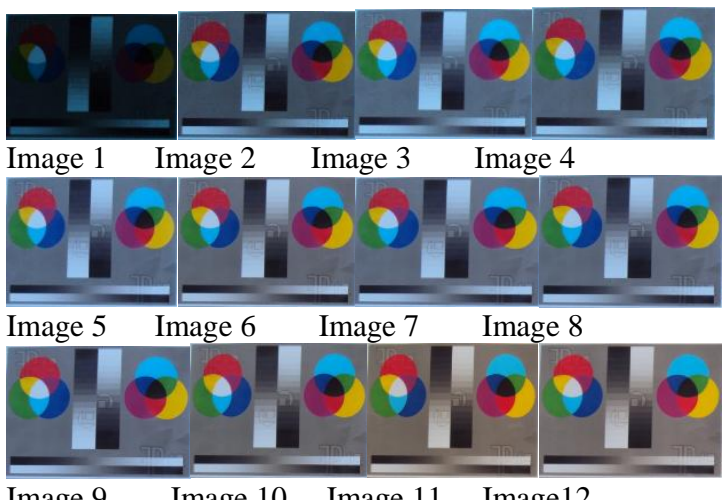




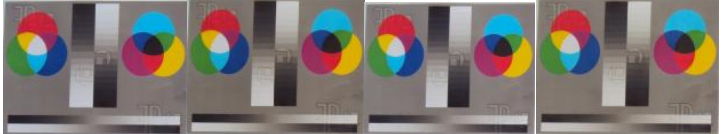

Image 13 Image 14 Image15 Image16

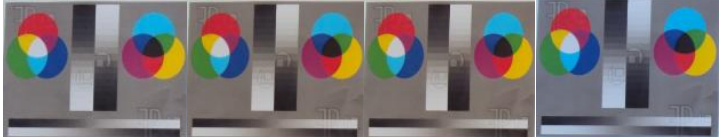

Image $17 \quad$ Image18 Image 19 Image 20

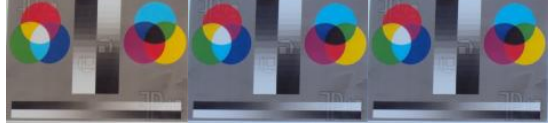

Image $21 \quad$ Image $22 \quad$ Image 23

Fig.3 The original image
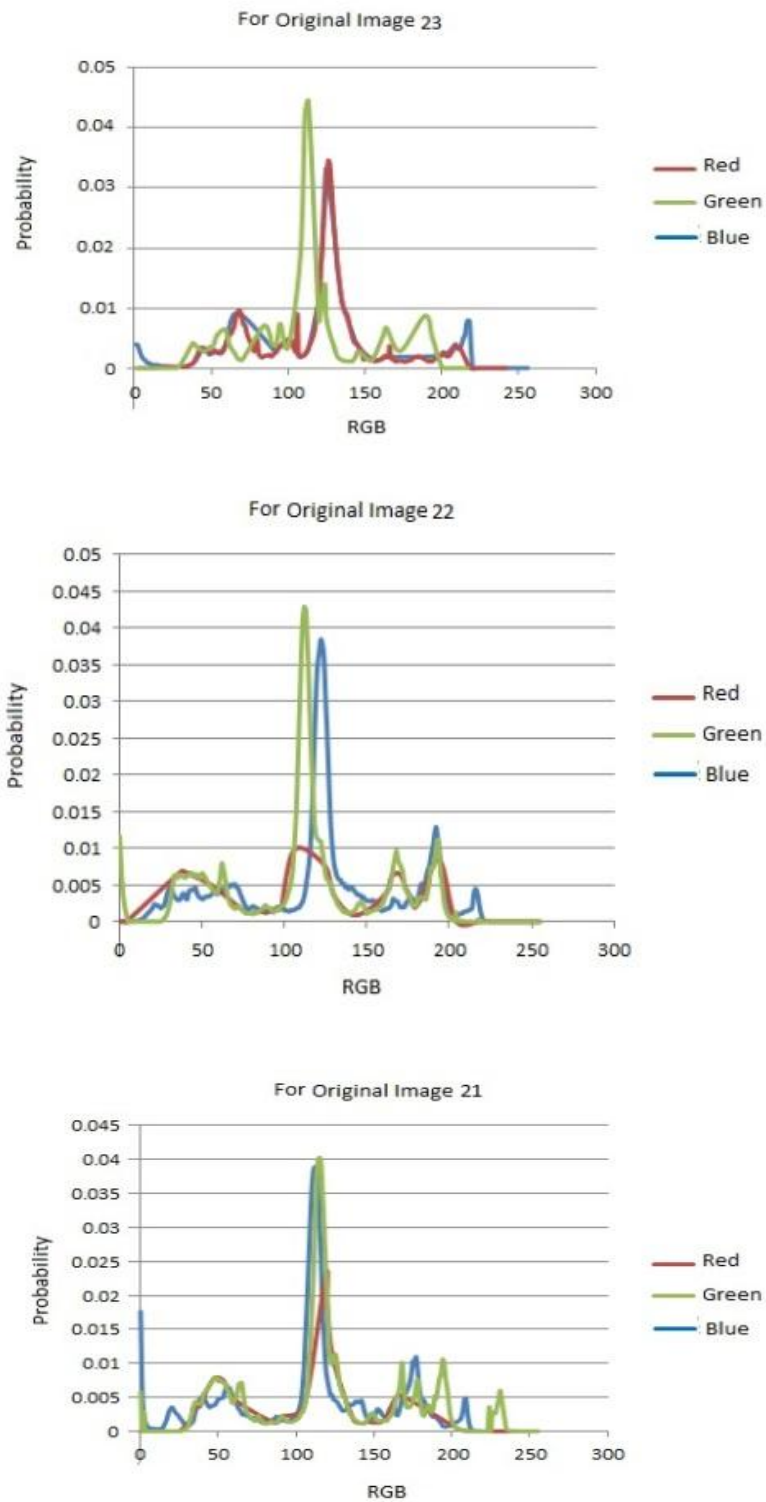
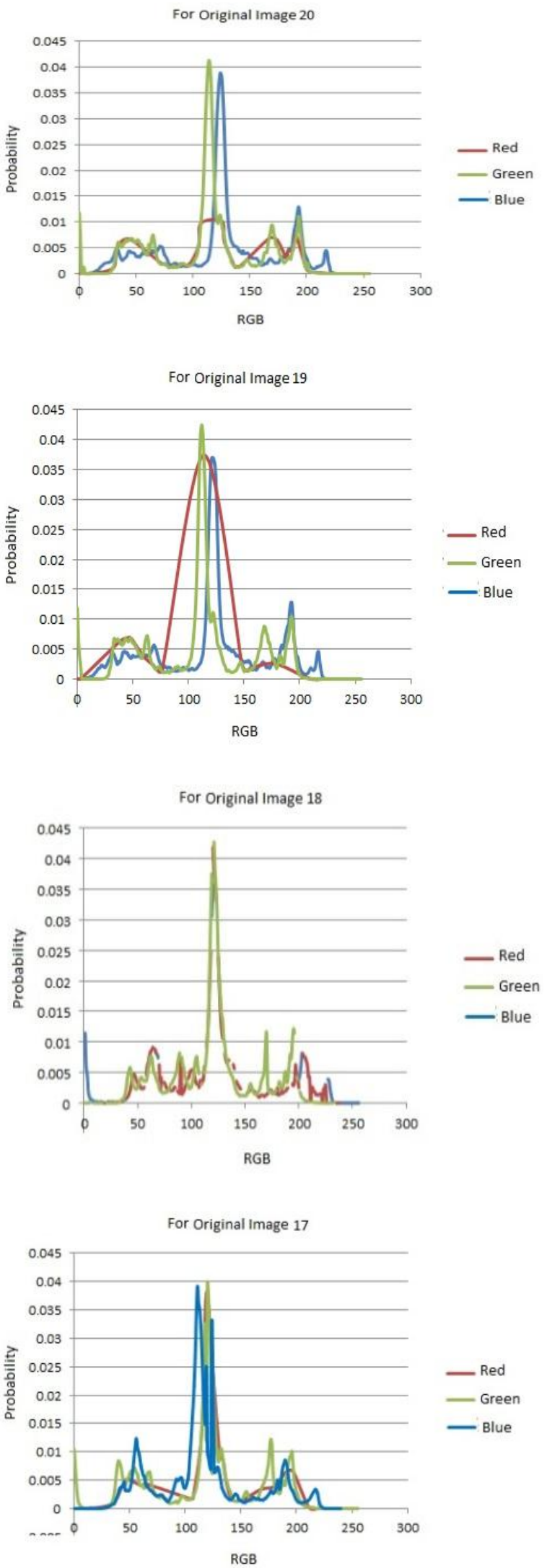

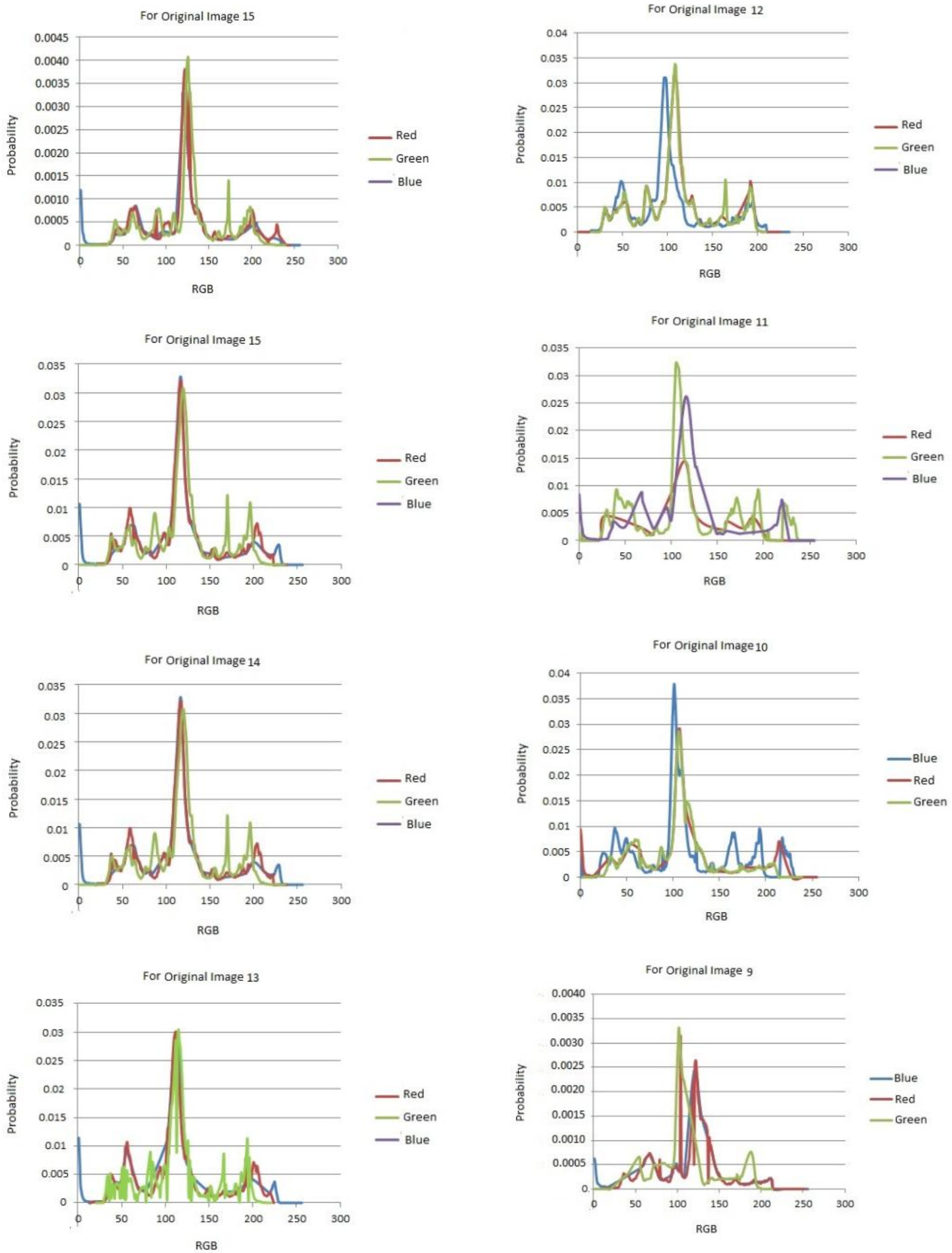

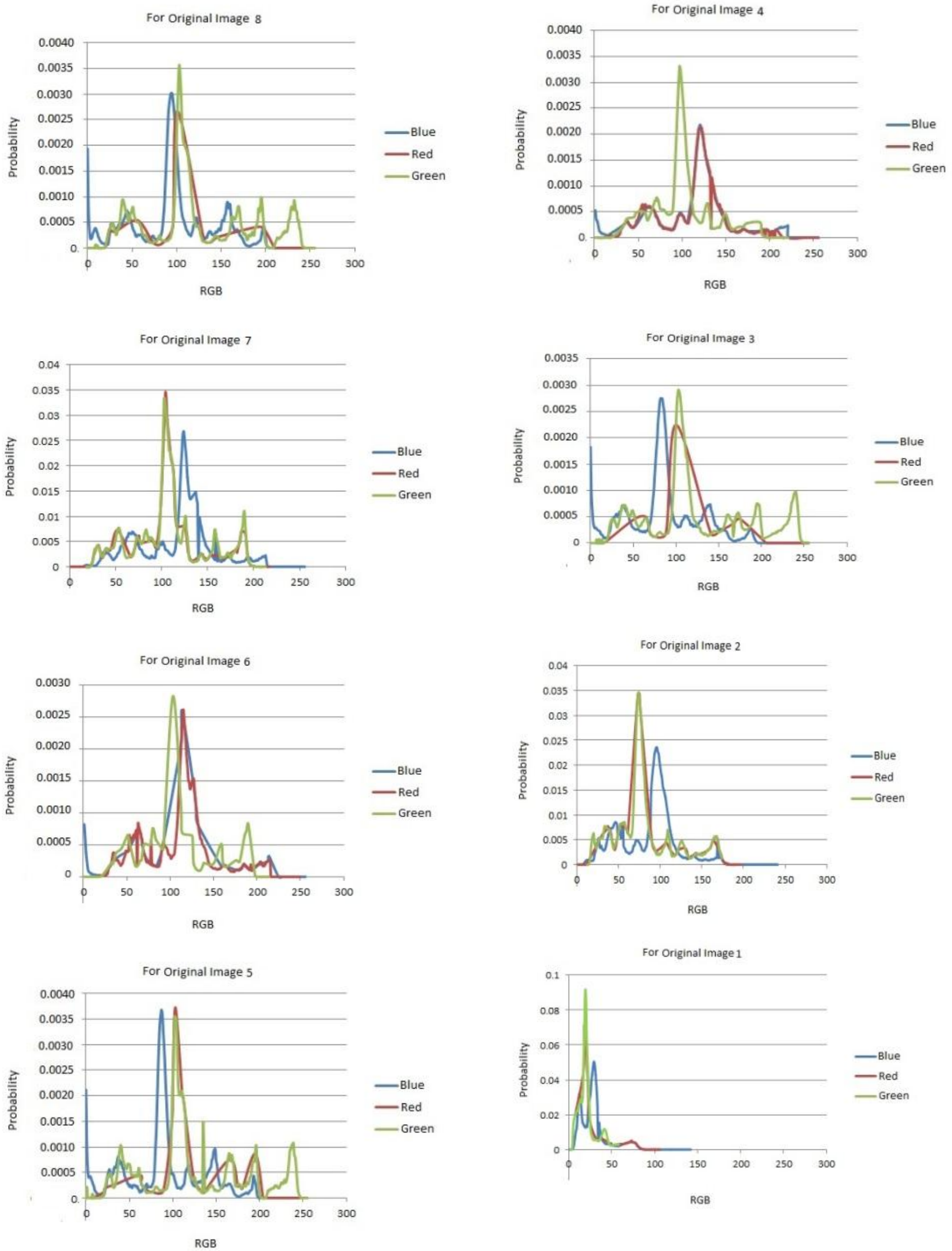

Fig.4 The histogram of original image 
After apply mean filter for all image and calculated mean \& histogram for read ,green, blue band .see the Fig.5 , for image after mean filter, and Fig 6 , for histogram.

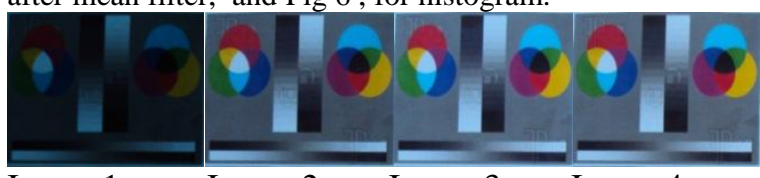

Image 1 Image 2 Image $3 \quad$ Image 4

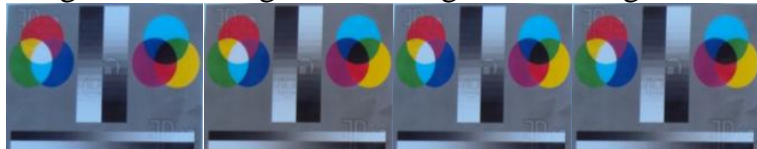

Image 5 Image 6 Image7 Image 8

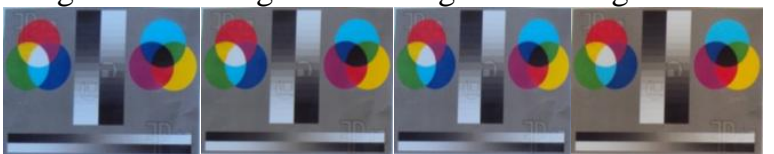

Image 9 Image $10 \quad$ Image $11 \quad$ Image 12

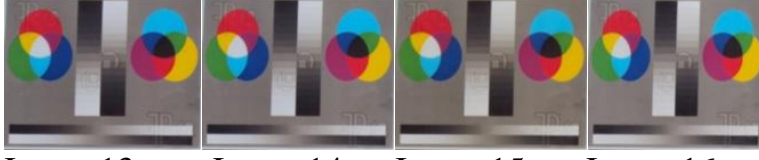

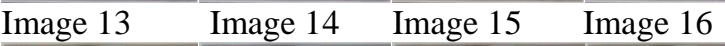

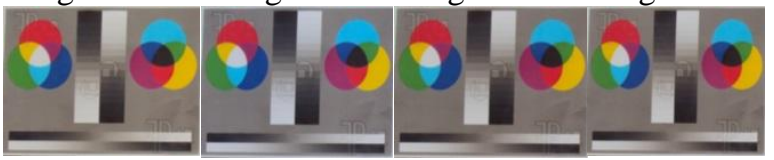

Image $17 \quad$ Image $18 \quad$ Image $19 \quad$ Image 20

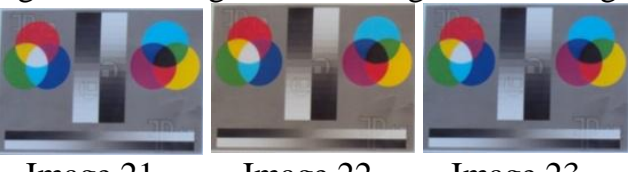

Image 21

Image 22

Image 23

Fig.5 The image after mean filter
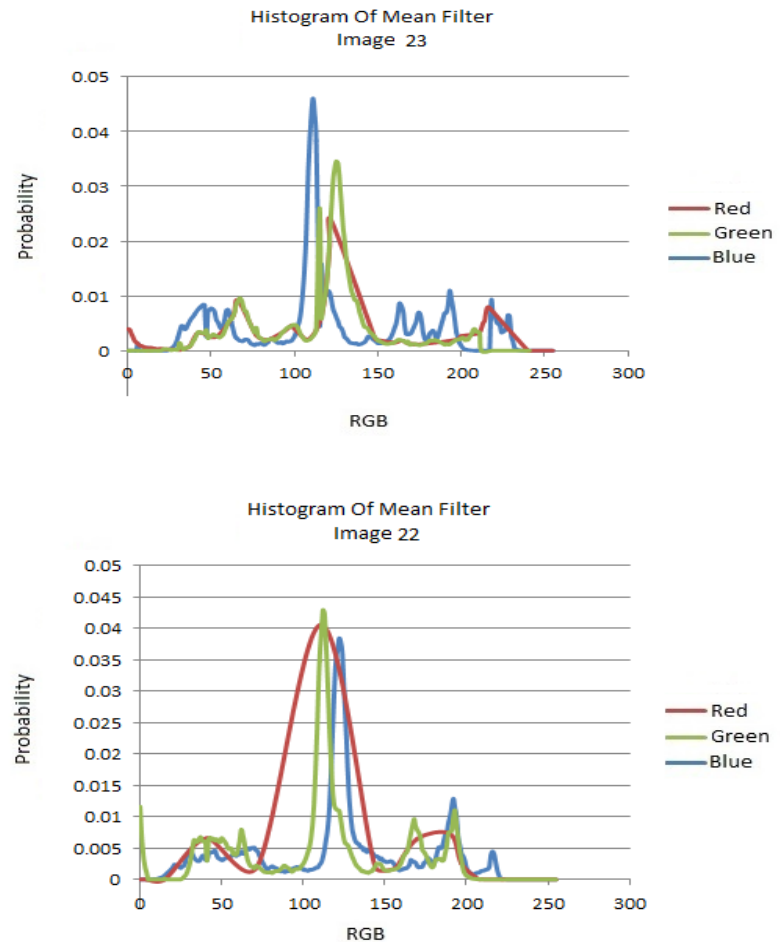
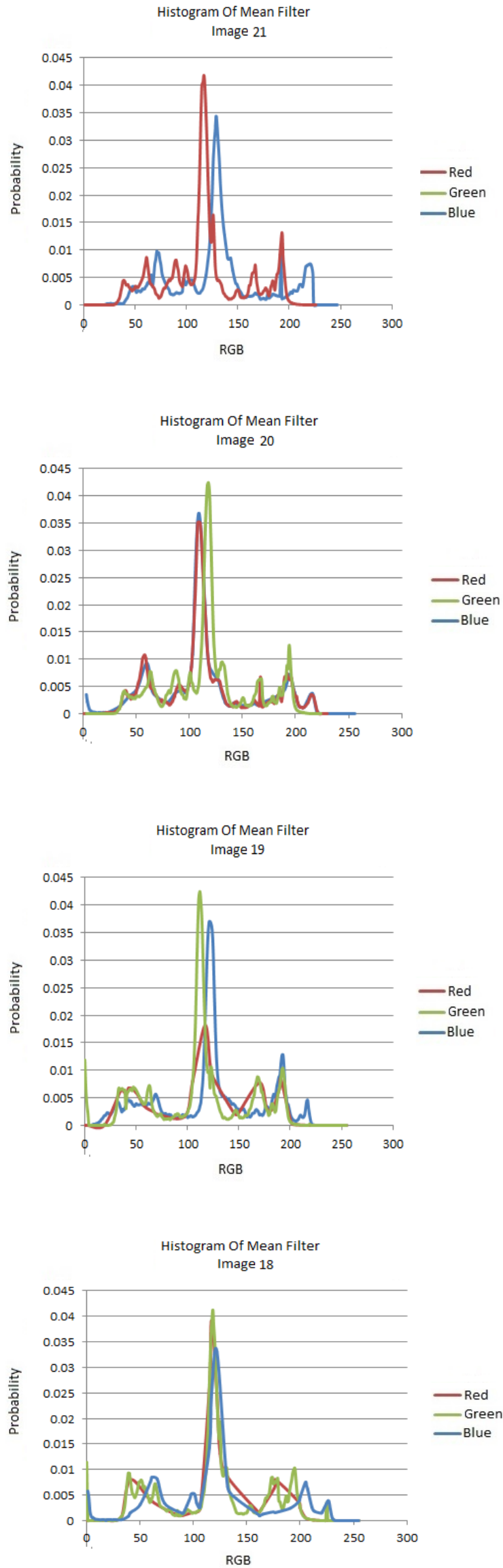

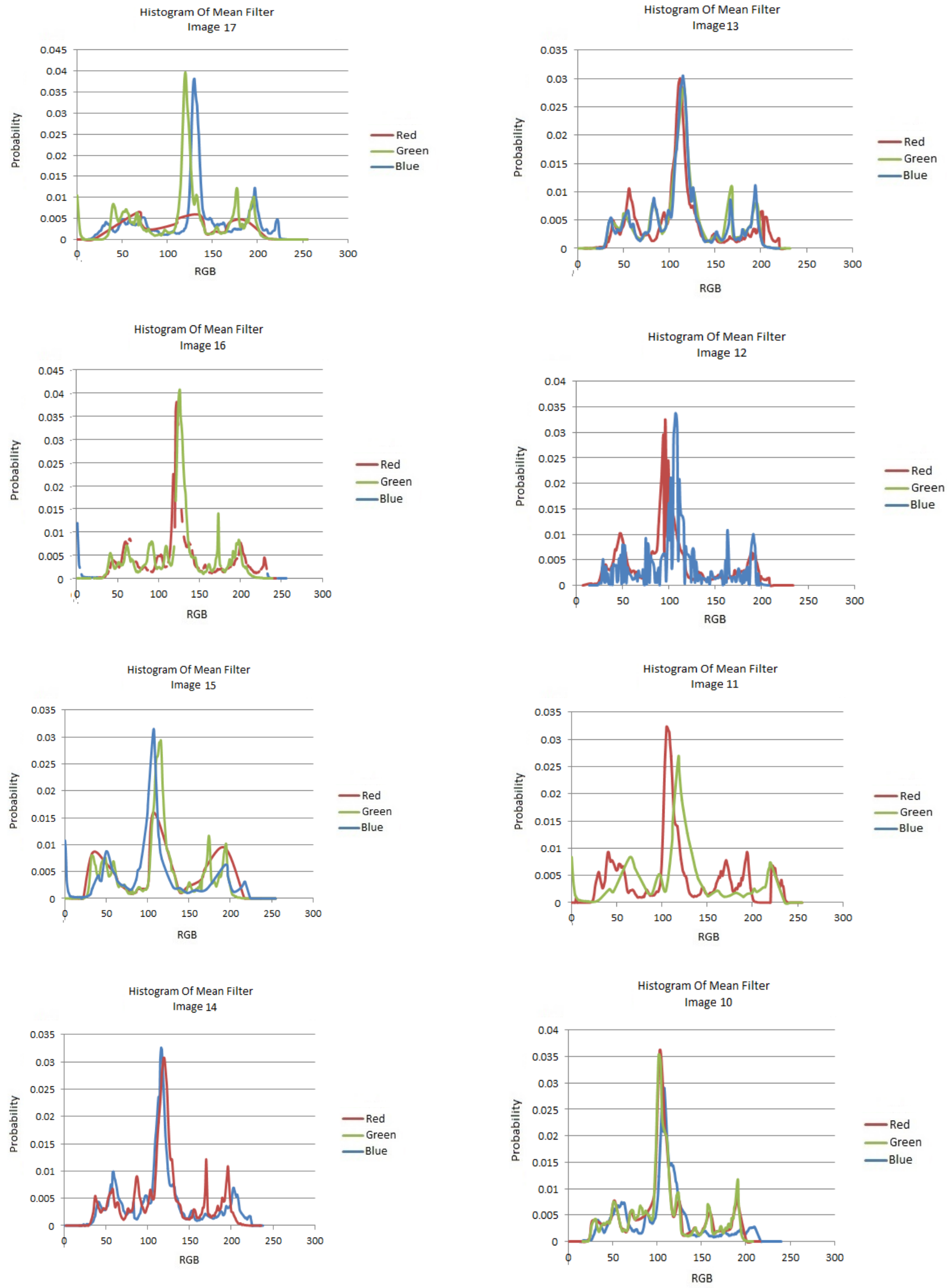

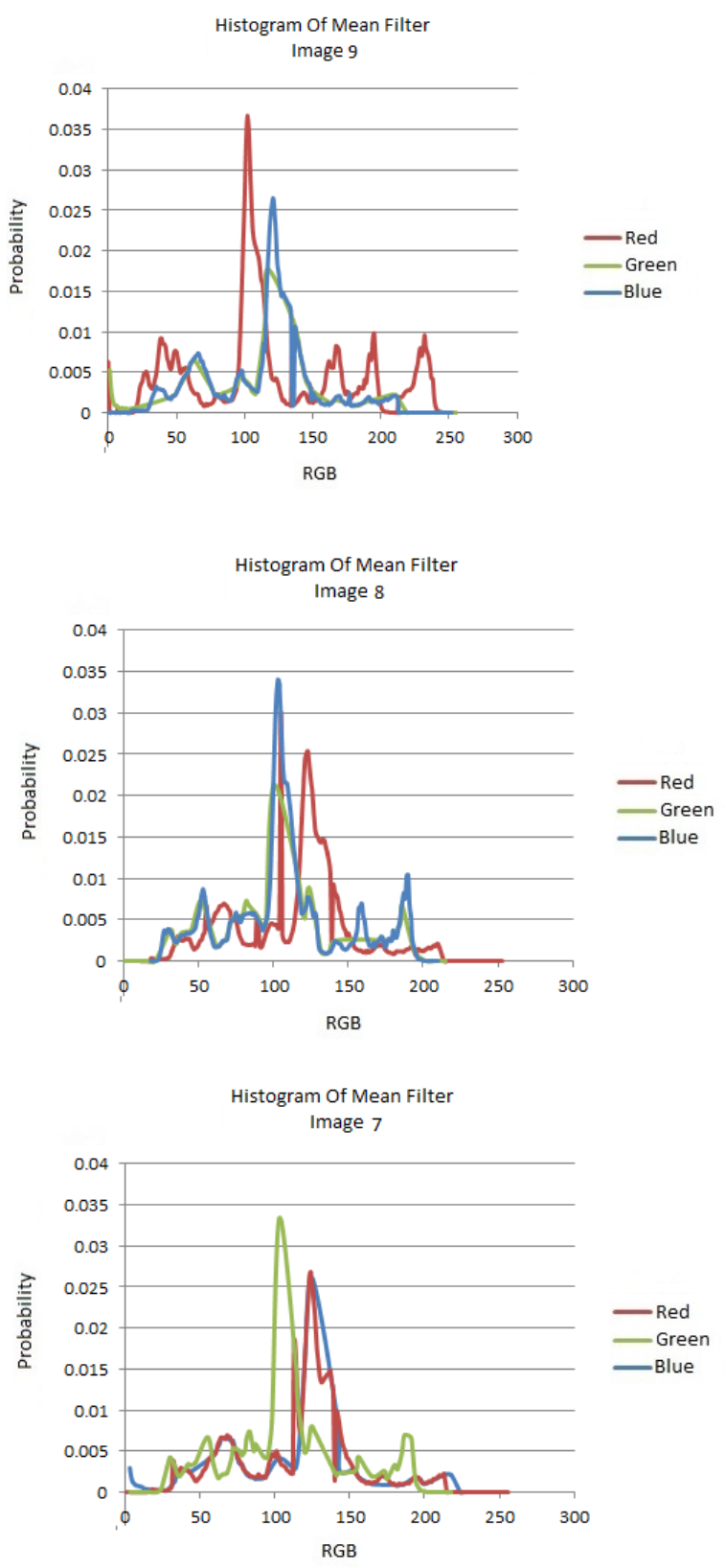

Histogram Of Mean Filter Image 6

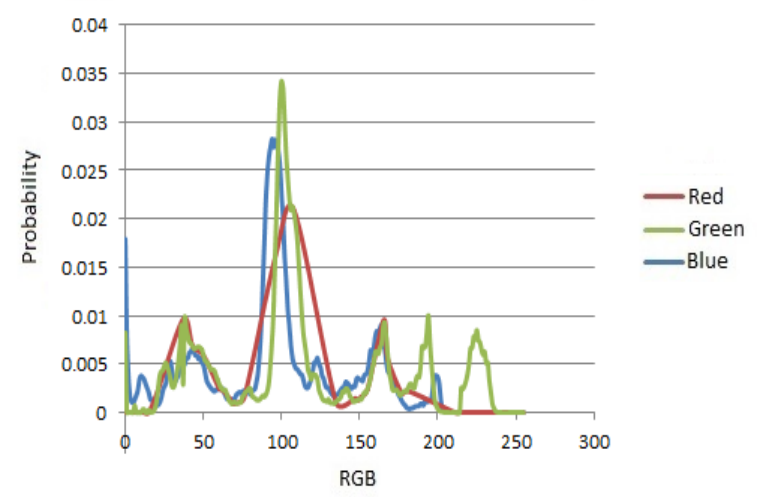

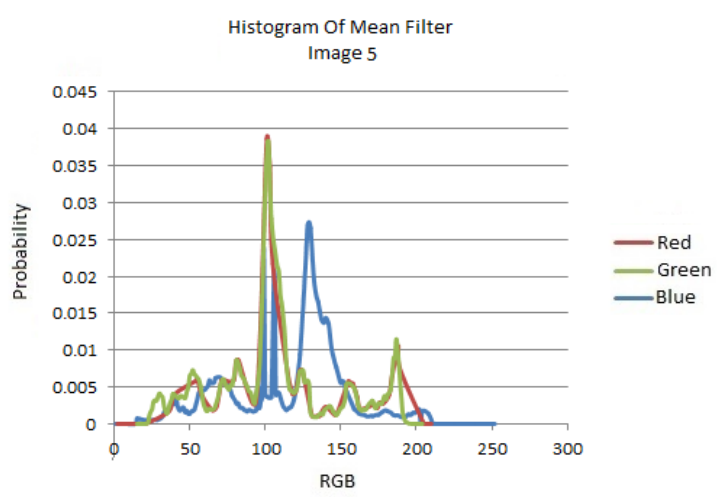
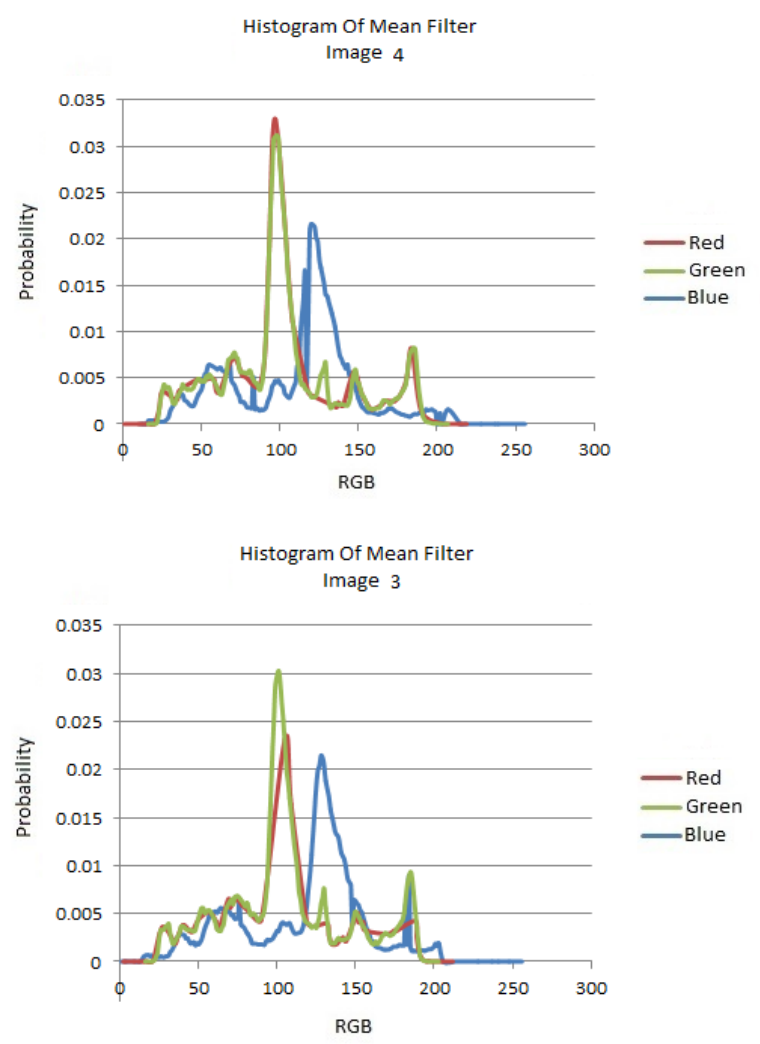

Histogram Of Mean Filter Image 2

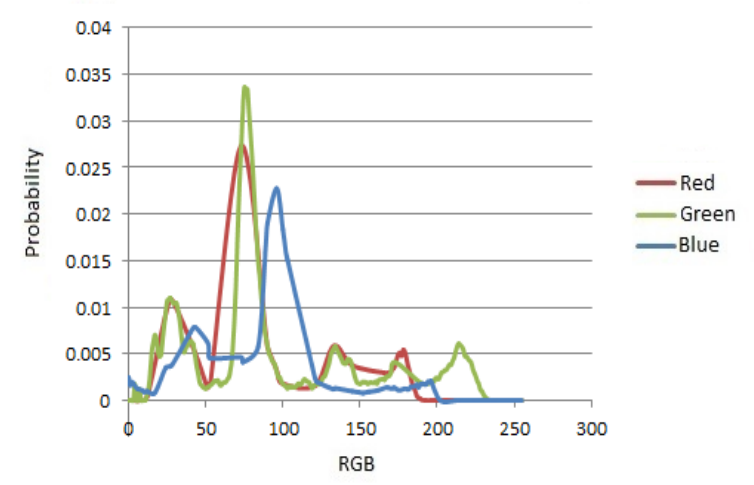




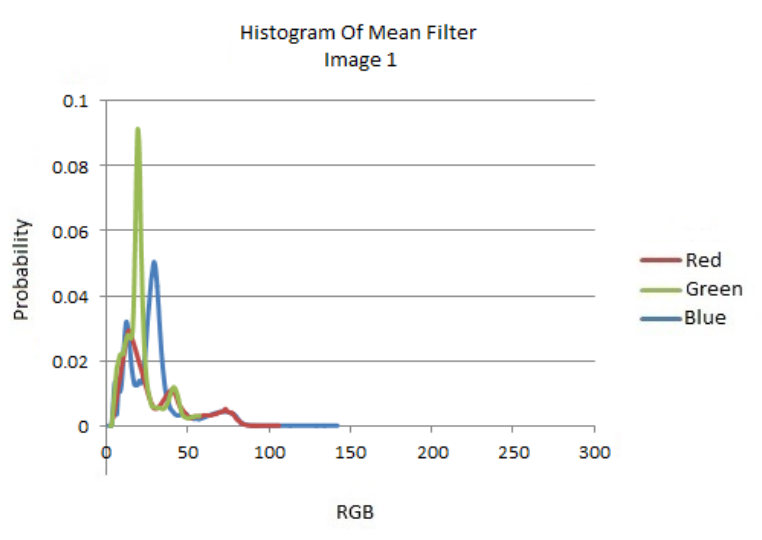

Fig.6 The histogram for image after mean filter.

Table.1 The properties of the all image in (RGB) by calculated (STD\& $\sigma)$. Note $(R 1, R 2, R 3)$ it is meaning ( $R$ red, Rgreen , $R$ blue)

\begin{tabular}{|c|c|c|c|c|c|c|c|c|}
\hline \multirow{2}{*}{ Mean } & \multicolumn{3}{|c|}{$\begin{array}{c}\text { Mean } \\
(\mu) \text { of homogenous } \\
\text { region }\end{array}$} & \multirow{2}{*}{\multicolumn{2}{|c|}{ STD }} & \multicolumn{3}{|c|}{$\begin{array}{c}\text { STD } \\
(\sigma) \text { of } \\
\text { homogenous } \\
\text { region }\end{array}$} \\
\hline & $\mathrm{R} 1$ & R2 & R3 & & & R1 & $\mathrm{R} 2$ & R3 \\
\hline 1 & 24 & 14 & 27 & 37 & 17 & 9.9 & 21 & 29 \\
\hline 2 & 80 & 65 & 83 & 103 & 37 & 35 & 43 & 54 \\
\hline 3 & 104 & 85 & 108 & 133 & 38 & 41 & 46 & 57 \\
\hline 4 & 101 & 85 & 104 & 125 & 39 & 41 & 46 & 57 \\
\hline 5 & 105 & 89 & 108 & 133 & 39 & 44 & 45 & 56 \\
\hline 6 & 104 & 97 & 105 & 120 & 40 & 46 & 42 & 54 \\
\hline 7 & 107 & 95 & 108 & 128 & 39 & 47 & 45 & 55 \\
\hline 8 & 106 & 95 & 108 & 127 & 39 & 45 & 45 & 55 \\
\hline 9 & 106 & 96 & 107 & 126 & 40 & 45 & 45 & 55 \\
\hline 10 & 106 & 103 & 106 & 113 & 40 & 47 & 45 & 53 \\
\hline 11 & 110 & 105 & 110 & 122 & 39 & 48 & 45 & 53 \\
\hline 12 & 109 & 116 & 106 & 100 & 40 & 50 & 46 & 48 \\
\hline 13 & 114 & 118 & 112 & 112 & 40 & 51 & 46 & 50 \\
\hline 14 & 118 & 122 & 116 & 116 & 40 & 52 & 46 & 50 \\
\hline 15 & 116 & 123 & 114 & 108 & 40 & 50 & 46 & 48 \\
\hline 16 & 124 & 129 & 112 & 121 & 40 & 52 & 46 & 49 \\
\hline
\end{tabular}

\begin{tabular}{|c|c|c|c|c|c|c|c|c|}
\hline 17 & 122 & 129 & 120 & 113 & 39 & 49 & 44 & 47 \\
\hline 18 & 120 & 122 & 119 & 121 & 39 & 50 & 44 & 49 \\
\hline 19 & 115 & 122 & 113 & 109 & 39 & 48 & 44 & 47 \\
\hline 20 & 117 & 123 & 115 & 110 & 39 & 48 & 44 & 47 \\
\hline 21 & 116 & 111 & 116 & 128 & 39 & 48 & 44 & 51 \\
\hline 22 & 115 & 112 & 113 & 109 & 39 & 48 & 44 & 47 \\
\hline 23 & 112 & 106 & 112 & 125 & 39 & 47 & 44 & 51 \\
\hline
\end{tabular}

A. The scanned part, we select three reign from image bund collar (RGB), every part of it have fore pixel , and calculate the (Mean of RGB \&STD of RGB \& Vr of RGB).see the Table. 2 and $3 \& 4$ and the Fig.7 is the image select reign .

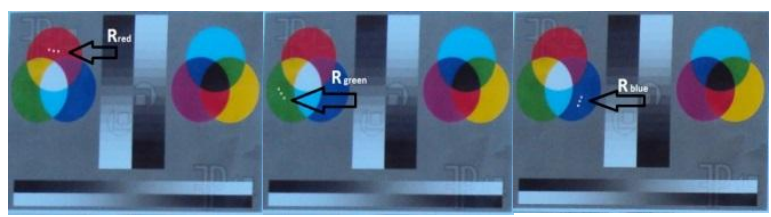

For reign red bund For reign green bund For reign blue bund Fig.7 The image of reign selected.

Table.2 The $(\mathbf{R} 1, \mathbf{R 2}, \mathbf{R 3})$ it is meaning ( $R$ red, Rgreen , $R$ blue)

\begin{tabular}{|c|c|c|c|c|c|c|c|c|c|}
\hline \multirow[t]{2}{*}{$\begin{array}{l}\text { No. of } \\
\text { image }\end{array}$} & \multicolumn{3}{|c|}{$\begin{array}{l}\text { Mean } \mathrm{R} \\
\text { Image for reign } \\
\text { red bund } \\
(\mu) \text { of } \\
\text { homogenous } \\
\text { region }\end{array}$} & \multicolumn{3}{|c|}{ 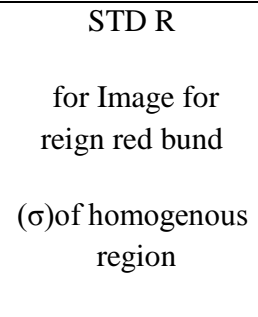 } & \multicolumn{3}{|c|}{$\begin{array}{c}\text { Vr R } \\
\text { Image for } \\
\text { reign red bund } \\
\text { The variance }\end{array}$} \\
\hline & $\mathrm{R} 1$ & $\overline{\mathrm{R} 2}$ & R3 & $\mathrm{R} 1$ & R2 & R3 & R1 & $\mathrm{R} 2$ & R3 \\
\hline 1 & 27 & 7 & 11 & 1.3 & 0.95 & 1.2 & 1.7 & 0.9 & 1.4 \\
\hline 2 & 121 & 25 & 46 & 2.21 & 2.3 & 2.3 & 4.9 & 5.3 & 5.5 \\
\hline 3 & 158 & 35 & 68 & 3.4 & 2.9 & 2.5 & 12 & 8.4 & 6.3 \\
\hline 4 & 153 & 34 & 60 & 3.2 & 2.6 & 2.9 & 10 & 7.1 & 8.8 \\
\hline 5 & 166 & 39 & 69 & 1.03 & 1.31 & 1.48 & 1.0 & 1.7 & 2.1 \\
\hline 6 & 171 & 38 & 62 & 2.2 & 1.6 & 2.1 & 5.0 & 2.8 & 4.6 \\
\hline 7 & 172 & 41 & 67 & 1.2 & 2.6 & 4.4 & 1.5 & 2.6 & 4.4 \\
\hline 8 & 170 & 39 & 65 & 1.6 & 1.3 & 1.4 & 2.6 & 1.8 & 2.0 \\
\hline 9 & 170 & 39 & 66 & 1.46 & 1.5 & 1.39 & 2.1 & 2.2 & 1.9 \\
\hline 10 & 176 & 38 & 58 & 1.6 & 2.1 & 1.7 & 2.8 & 4.7 & 3.1 \\
\hline
\end{tabular}




\begin{tabular}{|c|c|c|c|c|c|c|c|c|c|}
\hline 11 & 181 & 41 & 64 & 1.33 & 1.7 & 1.8 & 1.7 & 2.9 & 3.5 \\
\hline 12 & 191 & 30 & 48 & 3.1 & 1.7 & 1.8 & 10 & 3.03 & 3.3 \\
\hline 13 & 195 & 33 & 55 & 3.2 & 1.5 & 1.6 & 10 & 2.4 & 2.7 \\
\hline 14 & 201 & 35 & 58 & 2.6 & 2.1 & 2.3 & 7.1 & 4.7 & 5.4 \\
\hline 15 & 197 & 34 & 52 & 2.1 & 1.4 & 1.7 & 4.7 & 1.9 & 2.9 \\
\hline 16 & 206 & 36 & 57 & 2.7 & 1.44 & 1.63 & 7.4 & 2.08 & 2.6 \\
\hline 17 & 205 & 39 & 54 & 1.1 & 2.4 & 2.08 & 1.3 & 5.9 & 4.3 \\
\hline 18 & 197 & 40 & 61 & 2.04 & 2.09 & 2.31 & 4.1 & 4.3 & 5.3 \\
\hline 19 & 193 & 37 & 54 & 1.5 & 1.3 & 1.8 & 2.2 & 1.9 & 3.5 \\
\hline 20 & 196 & 40 & 56 & 1.3 & 1.1 & 2.3 & 1.7 & 1.3 & 5.7 \\
\hline 21 & 185 & 45 & 68 & 1.8 & 2.2 & 1.9 & 3.5 & 4.8 & 3.6 \\
\hline 22 & 192 & 36 & 54 & 1.37 & 1.38 & 1.57 & 1.8 & 1.9 & 2.4 \\
\hline 23 & 179 & 41 & 63 & 1.7 & 2.05 & 2.5 & 3.02 & 4.2 & 6.3 \\
\hline
\end{tabular}

Table.3 The (R1, R2, R3)it is meaning(Rred,

\section{Rgreen,Rblue)}

\begin{tabular}{|c|c|c|c|c|c|c|c|c|c|}
\hline \multirow{3}{*}{$\begin{array}{c}\text { No. } \\
\text { of } \\
\text { ima } \\
\text { ge }\end{array}$} & \multirow{2}{*}{\multicolumn{3}{|c|}{$\begin{array}{l}\text { Mean } \mathrm{G} \\
\text { mage for reign } \\
\text { green bund } \\
\quad(\mu) \text { of } \\
\text { homogenous } \\
\text { region }\end{array}$}} & \multirow{2}{*}{\multicolumn{3}{|c|}{$\begin{array}{c}\text { STD G } \\
\text { for Image for reign } \\
\text { Green bund } \\
\text { ( } \sigma) \text { of homogenous } \\
\text { region }\end{array}$}} & \multirow{2}{*}{\multicolumn{3}{|c|}{$\begin{array}{c}\text { Vr G } \\
\text { Image for } \\
\text { reign green } \\
\text { bund } \\
\text { The variance }\end{array}$}} \\
\hline & & & & & & & & & \\
\hline & $\mathrm{R} 1$ & $\mathrm{R} 2$ & R3 & R1 & $\mathrm{R} 2$ & R3 & $\mathrm{R} 1$ & R2 & R3 \\
\hline 1 & 6 & 20 & 10 & 2.1 & 1.3 & 1.3 & 4 & 1.7 & 1.7 \\
\hline 2 & 28 & 79 & 42 & 6.3 & 2.2 & 2.8 & 40 & 5.0 & 8.1 \\
\hline 3 & 39 & 110 & 58 & 4.1 & 2.1 & 2.46 & 17 & 4.4 & 6.0 \\
\hline 4 & 38 & 106 & 53 & 2.9 & 1.6 & 2.9 & 7 & 2.7 & 8.8 \\
\hline 5 & 39 & 113 & 66 & 2.9 & 1.8 & 2.2 & 8 & 3.3 & 5.1 \\
\hline 6 & 48 & 112 & 58 & 1.9 & 1.3 & 1.8 & 3 & 1.6 & 3.2 \\
\hline 7 & 46 & 115 & 64 & 4.3 & 1.4 & 2.9 & 17 & 2.0 & 8.9 \\
\hline 8 & 45 & 114 & 63 & 2.91 & 1.5 & 1.9 & 8 & 2.4 & 3.6 \\
\hline 9 & 46 & 114 & 63 & 2.8 & 1.4 & 2.4 & 8 & 2 & 5.9 \\
\hline 10 & 55 & 113 & 55 & 2.4 & 1.8 & 1.7 & 6 & 3.6 & 2.9 \\
\hline
\end{tabular}

\begin{tabular}{|c|c|c|c|c|c|c|c|c|c|}
\hline 11 & 55 & 120 & 66 & 1.5 & 1.3 & 1.6 & 2 & 1.7 & 2.6 \\
\hline 12 & 64 & 119 & 48 & 2.6 & 1.5 & 3.3 & 6 & 2.3 & 11 \\
\hline 13 & 62 & 125 & 58 & 2.1 & 1.5 & 1.6 & 4 & 2.5 & 2.8 \\
\hline 14 & 63 & 130 & 61 & 2.0 & 1.9 & 2.6 & 4 & 3.7 & 6.7 \\
\hline 15 & 67 & 126 & 51 & 2.1 & 1.5 & 2.3 & 4 & 2.5 & 5.5 \\
\hline 16 & 71 & 138 & 64 & 3.1 & 1.3 & 2.0 & 9 & 1.7 & 4.4 \\
\hline 17 & 74 & 133 & 57 & 2.29 & 1.4 & 2.4 & 5 & 2.1 & 6.1 \\
\hline 18 & 66 & 130 & 64 & 3.2 & 1.7 & 1.8 & 10 & 3.1 & 3.5 \\
\hline 19 & 68 & 123 & 53 & 1.3 & 0.9 & 1.9 & 1 & 0.8 & 3.7 \\
\hline 20 & 70 & 125 & 56 & 1.4 & 1.8 & 2.2 & 2 & 3.4 & 5.2 \\
\hline 21 & 58 & 126 & 72 & 1.41 & 1.5 & 1.6 & 1. & 2.5 & 2.6 \\
\hline 22 & 68 & 122 & 53 & 2.0 & 1.8 & 1.5 & 4. & 3.5 & 2.4 \\
\hline 23 & 53 & 121 & 69 & 1.2 & 1.1 & 1.8 & 1 & 1.2 & 3 \\
\hline
\end{tabular}

Table.4 The( $R 1, R 2, R 3)$ it is meaning( $R$ red, $R$ green , $R$ blue)

\begin{tabular}{|c|c|c|c|c|c|c|c|c|c|}
\hline \multirow{2}{*}{$\begin{array}{l}\text { No. } \\
\text { of } \\
\text { ima } \\
\text { ge }\end{array}$} & & $\begin{array}{l}\text { Mean } \\
\text { ge for } \\
\text { ue bu } \\
\text { homo } \\
\text { regio }\end{array}$ & ign & & $\begin{array}{l}\text { STD } \\
\text { lage } f \\
\text { lue bu } \\
\text { homo } \\
\text { regio }\end{array}$ & $\begin{array}{l}\text { reign } \\
\text { nous }\end{array}$ & & $\begin{array}{l}\text { Vr B } \\
\text { ue for } \\
\text { ue bu }\end{array}$ & $\begin{array}{l}\text { eign } \\
d\end{array}$ \\
\hline & $\mathrm{R} 1$ & $\mathrm{R} 2$ & R3 & R1 & R2 & R3 & R1 & R2 & R3 \\
\hline 1 & 3 & 11 & 32 & 1 & 1.1 & 3 & 1 & 1.2 & 9.2 \\
\hline 2 & 5 & 42 & 107 & 3.3 & 1.8 & 3.1 & 11 & 3.2 & 9.9 \\
\hline 3 & 3.3 & 2.1 & 2.2 & 3.3 & 2.1 & 2.2 & 11 & 4.6 & 5.1 \\
\hline 4 & 9 & 64 & 144 & 5.6 & 2 & 2.4 & 32 & 4 & 6 \\
\hline 5 & 4 & 62 & 151 & 1.2 & 1.4 & 1.42 & 1.6 & 2.1 & 2 \\
\hline 6 & 13 & 57 & 135 & 2 & 1 & 2 & 4 & 1.6 & 4.5 \\
\hline 7 & 11 & 61 & 144 & 3.4 & 1.3 & 2.2 & 11 & 1.8 & 4.8 \\
\hline 8 & 6 & 58 & 142 & 1.9 & 1.6 & 1.7 & 3.9 & 2.7 & 3.1 \\
\hline 9 & 9 & 58 & 142 & 2.2 & 1.2 & 1.7 & 5.1 & 1.6 & 3.1 \\
\hline 10 & 19 & 57 & 130 & 1.5 & 1.5 & 1.88 & 2.3 & 2.2 & 3.5 \\
\hline
\end{tabular}




\begin{tabular}{|c|c|c|c|c|c|c|c|c|c|}
\hline 11 & 14 & 58 & 135 & 2.1 & 1.7 & 1.4 & 4.5 & 2.9 & 2.1 \\
\hline 12 & 23 & 53 & 113 & 1.3 & 1.3 & 2.2 & 1.7 & 1.8 & 4.9 \\
\hline 13 & 18 & 56 & 126 & 2.44 & 1.51 & 1.9 & 5.9 & 2.2 & 3.6 \\
\hline 14 & 22 & 59 & 131 & 2 & 1.4 & 1.8 & 4.1 & 2.2 & 3.4 \\
\hline 15 & 25 & 60 & 123 & 1.3 & 1.6 & 1.7 & 1.9 & 2.5 & 2.9 \\
\hline 16 & 24 & 65 & 138 & 2.3 & 1.3 & 2.5 & 5.3 & 1.9 & 6.7 \\
\hline 17 & 31 & 68 & 130 & 1.9 & 1.3 & 1.8 & 3.9 & 1.9 & 3.2 \\
\hline 18 & 25 & 64 & 136 & 1.6 & 1.2 & 1.4 & 2.8 & 1.6 & 1.9 \\
\hline 19 & 29 & 63 & 125 & 2.1 & 1.2 & 1.8 & 4.7 & 1.4 & 3.3 \\
\hline 20 & 32 & 65 & 128 & 2.2 & 1.8 & 2.4 & 4.8 & 3.4 & 5.8 \\
\hline 21 & 20 & 64 & 143 & 3.1 & 1.7 & 1.4 & 9.8 & 2.9 & 2.1 \\
\hline 22 & 30 & 64 & 125 & 1.8 & 1.4 & 1.8 & 3.2 & 2.1 & 3.4 \\
\hline 23 & 18 & 60 & 139 & 2.3 & 1.6 & 1.2 & 5.3 & 2.6 & 1.6 \\
\hline
\end{tabular}
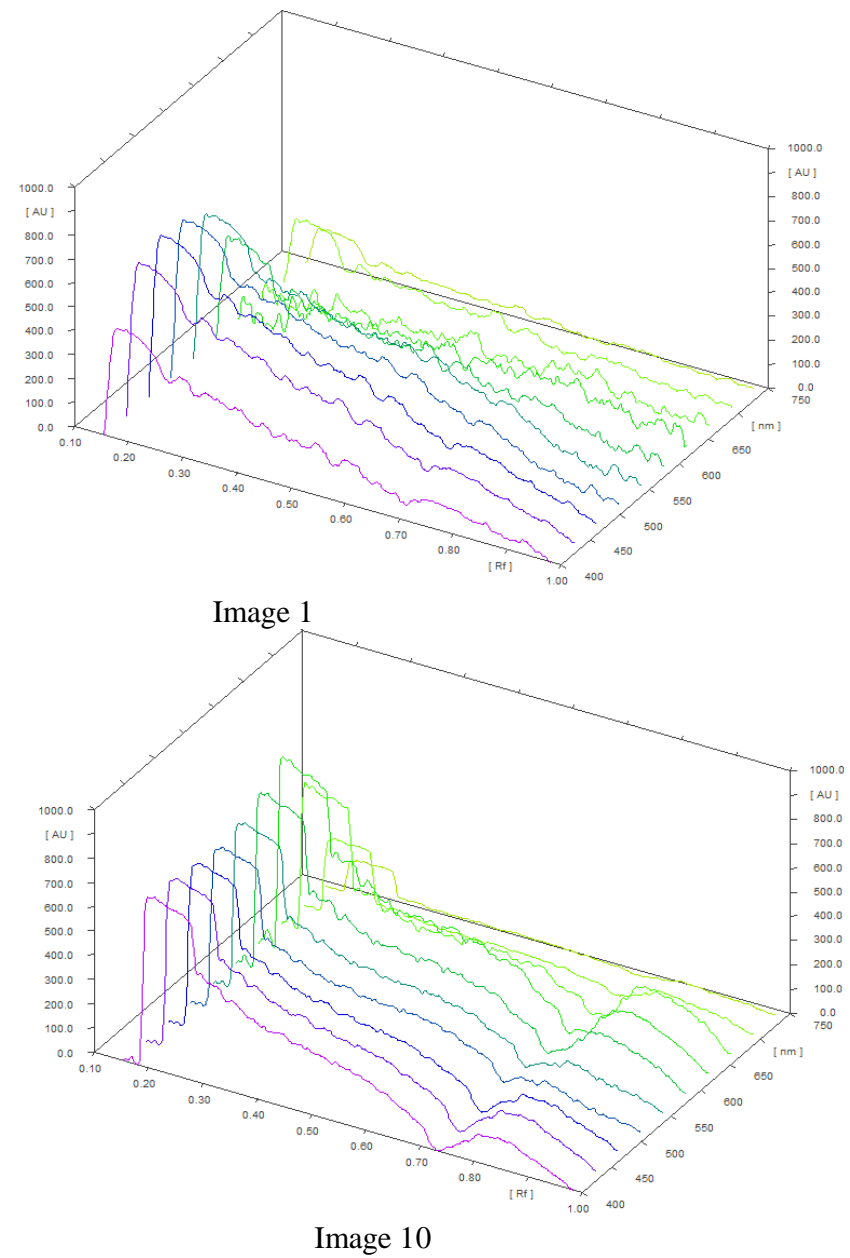

Fig.9. the absorbed in different wavelengths for image

We take image No.1, 2,3,4,5,6,7,8 and 9 to capture image from Visualizer in deferent wave length $(254,366) \mathrm{nm}$ see the Fig.10.

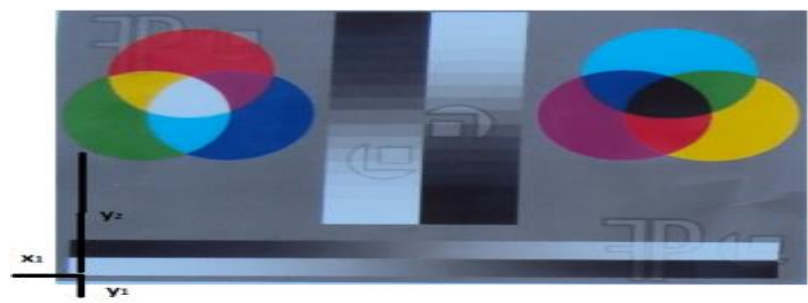

Fig.8 The line of image it starts

The difference can be seen from Fig.9, The clarity of descendants of variation in the severity of absorbed and reflected between the different wavelengths and each of the following wavelengths $(400,428$

$, 438,461,476,514,552,590.628,666,704,742) \mathrm{nm}$. See the Fig.9.

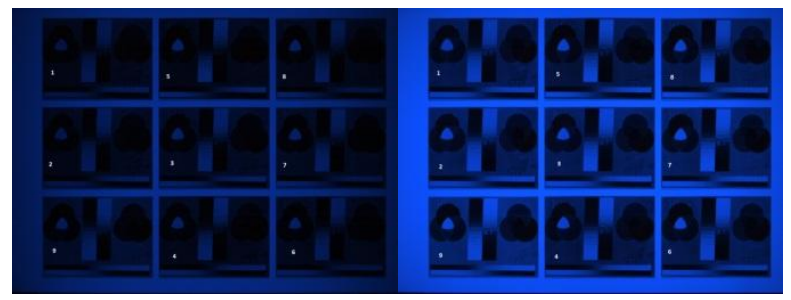

Image in $254 \mathrm{~nm}$ capture.

Image in $366 \mathrm{~nm}$ capture

Fig.10. capture image in $366 \& 254 \mathrm{~nm}$.

We work in image No.1\& 9 to calculate properties image also we select three reigns for pixel form image to see the band of colures see the Fig.11. 

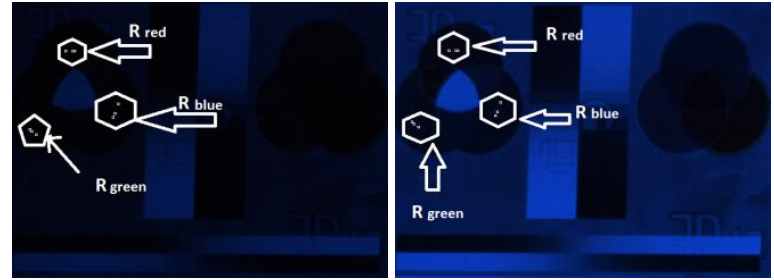

Fig.11 Image No. $1 \& 9$ reign location at 254 nm:Image No. $1 \& 9$ reign location at $366 \mathrm{~nm}$.

The image histogram in $255 \mathrm{~nm}$ and $366 \mathrm{~nm}$ in the Fig.12, and the Table. 5 the (RGB) result from the image.

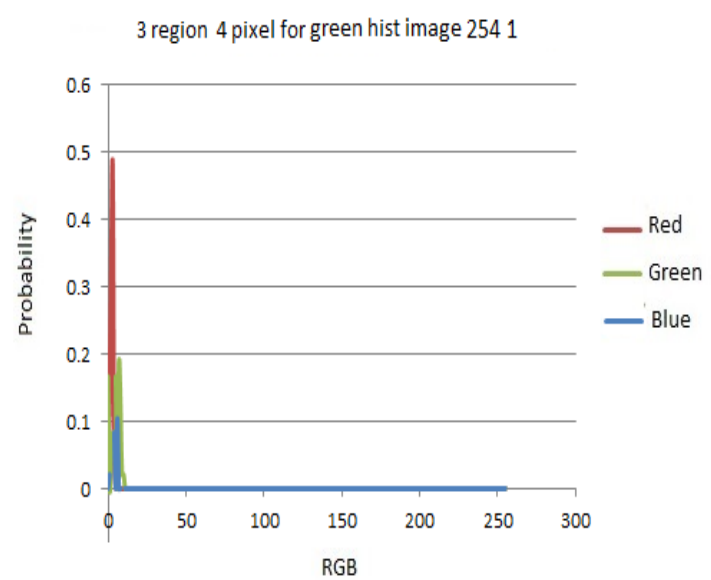

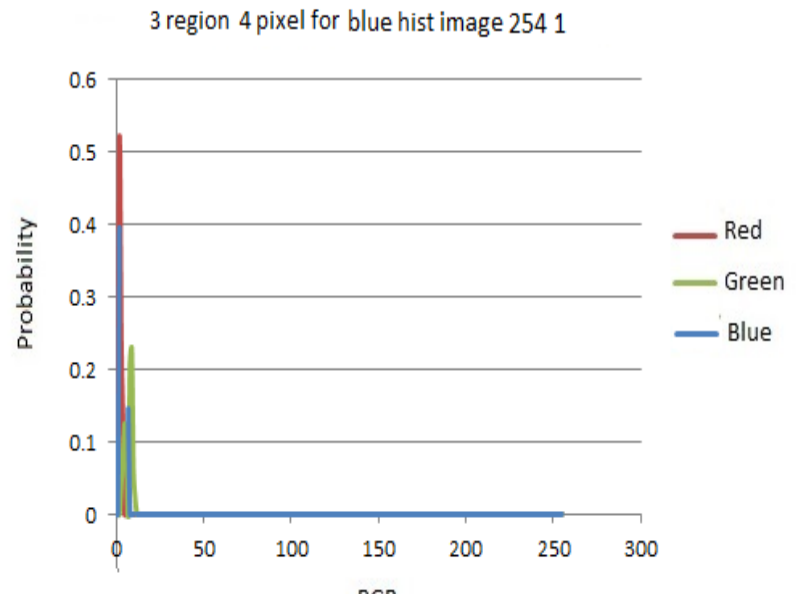

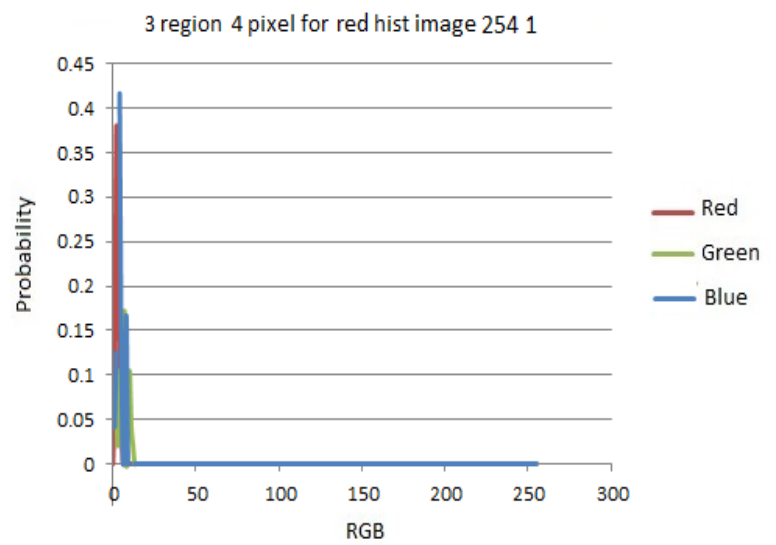

This histogram for (Red :Green :Blue) at 254nm image No.1

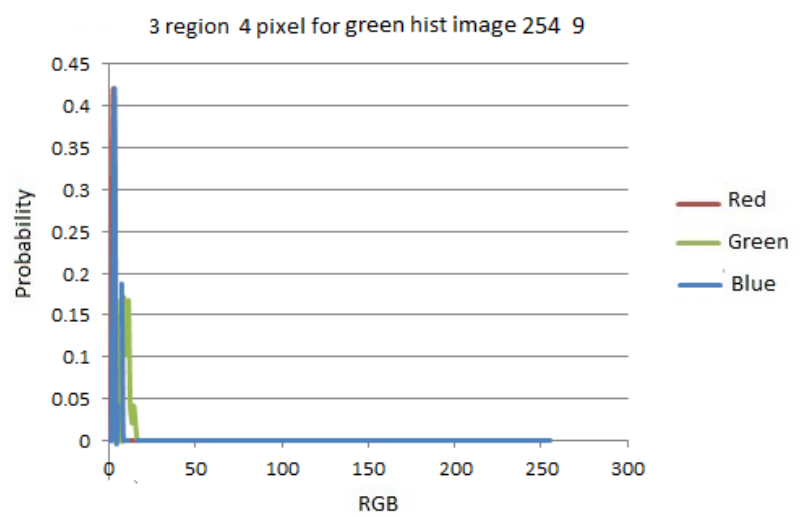



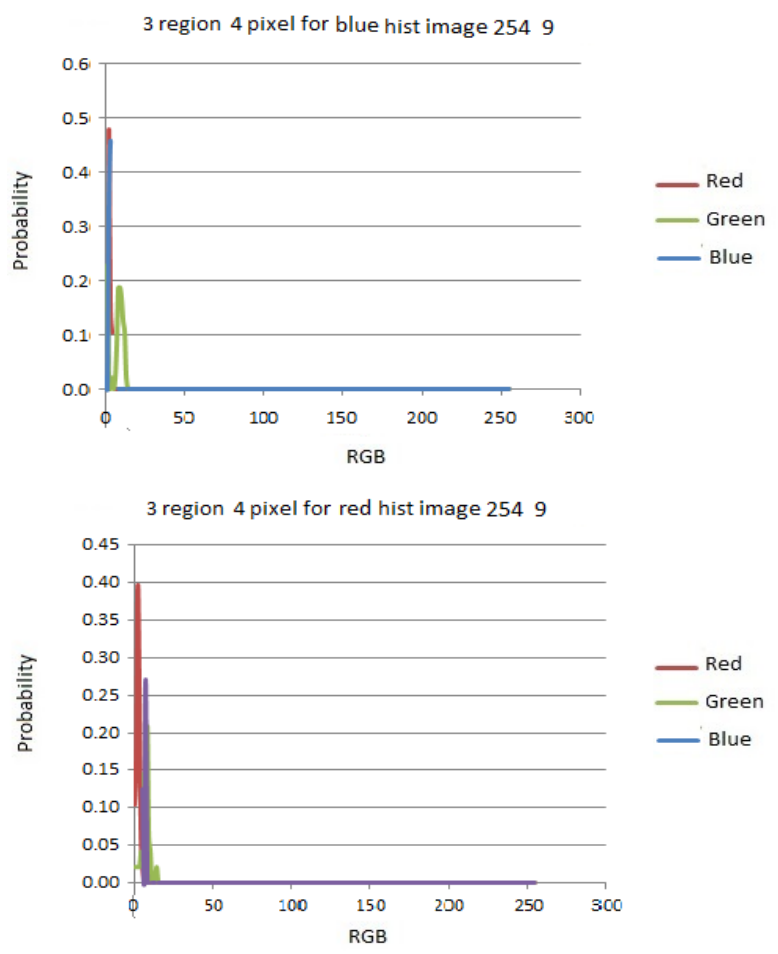

This histogram for (Red: Green: Blue) at 254nm image No.9
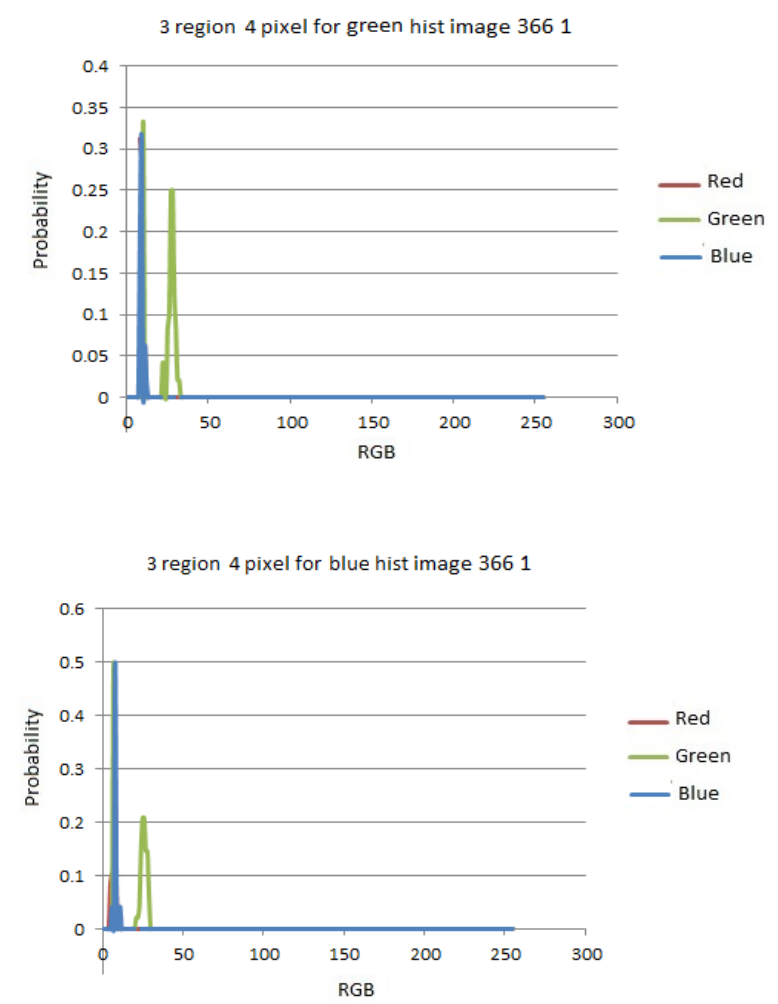

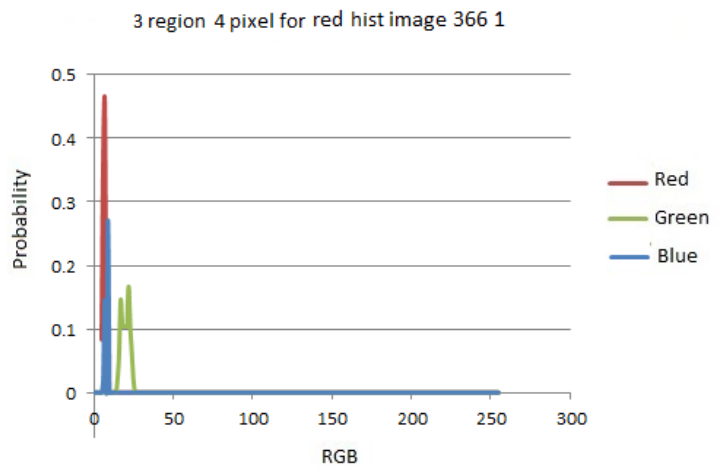

This histogram for (Red: Green: Blue) at $366 \mathrm{~nm}$ image No.1
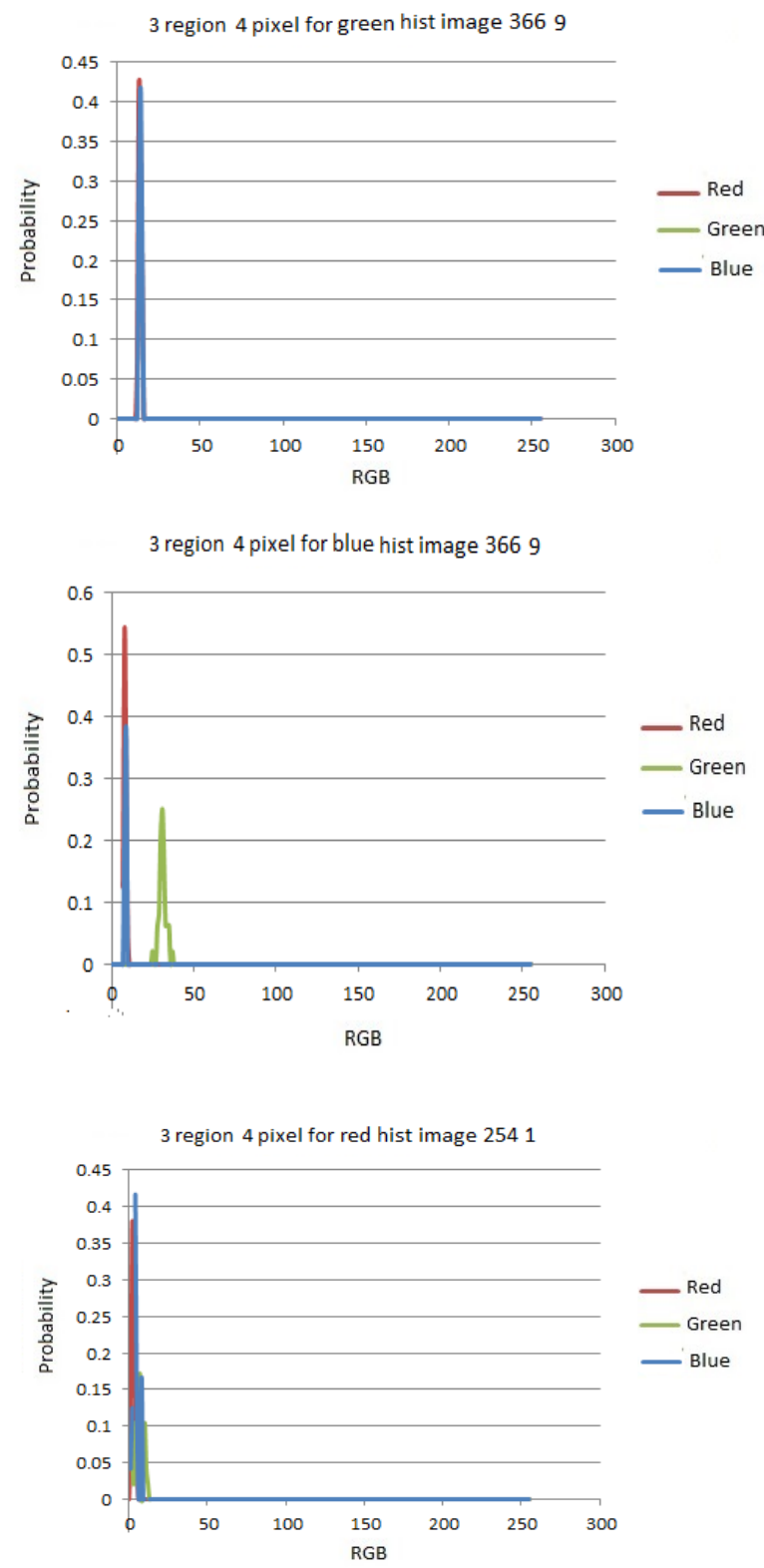

Fig.12 this histogram for (Red: Green: Blue) at $366 \mathrm{~nm}$ image No.9. 
Table.5 the (R1, R2, R3) it is meaning ( $R$ red, Rgreen , $R$ blue)

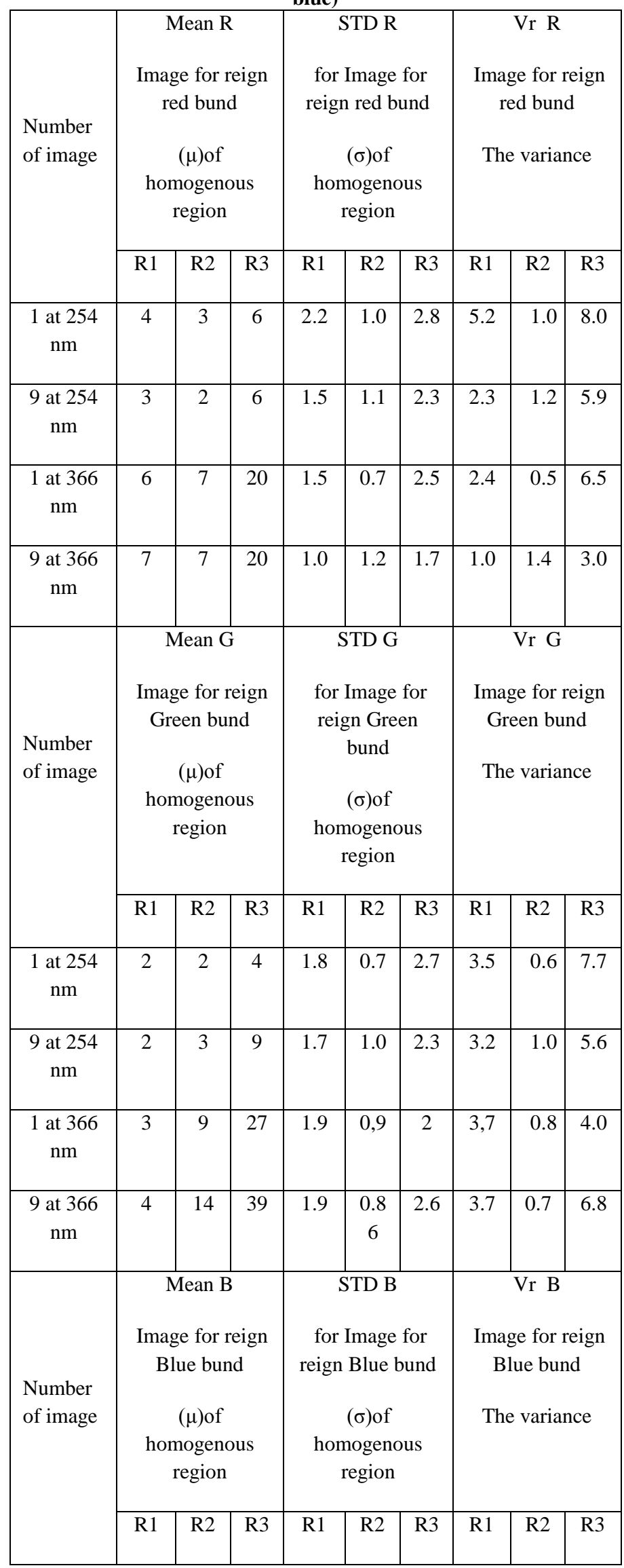

\begin{tabular}{|c|c|c|c|c|c|c|c|c|c|}
\hline $\begin{array}{c}1 \text { at } 254 \\
\mathrm{~nm}\end{array}$ & 2 & 2 & 7 & 1.9 & 0,8 & 1.9 & 3.9 & 0.6 & 3.9 \\
\hline $\begin{array}{c}9 \text { at } 254 \\
\mathrm{~nm}\end{array}$ & 1 & 2 & 8 & 1.4 & 0.9 & 2.4 & 2.0 & 0.9 & 5.8 \\
\hline $\begin{array}{c}1 \text { at } 366 \\
\mathrm{~nm}\end{array}$ & 3 & 7 & 25 & 1.8 & 1.0 & 1.8 & 3.3 & 1.1 & 3.2 \\
\hline $\begin{array}{c}9 \text { at } 366 \\
\mathrm{~nm}\end{array}$ & 2 & 8 & 31 & 1.6 & 0.7 & 2.1 & 2.8 & 0.5 & 4.5 \\
\hline
\end{tabular}

\section{RESULTS OF EXTRACT FROM IMAGE}

One image have been properties (Iw*Ih) 498*363 bit plane 24bpp and the smoothing effects, this is, image have size (256X256) and grays ranged between 0 (dark) to 256 (bright). The results obtained by perform each of mean filters are demonstrated as follows:

- $\quad$ Fig.3, represent the original images (i.e. the image Taken from camera original, noisy) .The histograms of the original image are shown in Fig.3. The histograms results are for original. After application Mean filter on the original images, the result in the Fig.5, the histograms of the original image are shown in Fig.6. The properties of all image in (RGB) by calculated (STD \& $\sigma$ ) in the table (1-1)

- Three homogenous regions have been selected to compute the mean $(\mu)$ and the variance $(\mathrm{Vr})$, for each image region within all original, noisy in the Table. (2), (3) \& (4). And filtered images. These values have been used to judge the performance of the adopted results of the original image. And preserved $\mu$ values constant. Another quality test has been carried on the selected regions of all noisy.

\section{DISCUSSION}

Tables Conclusion According to the quantitative measures given in Table.1, in which the mean, the STD homogenous, the adopted can be discussed as follows:

- We can see the increase over time based on the increase in sunlight

Even up to the highest value and return to the descent (on STD \& $\sigma$ ), the reason towards the sun goes down, so the Red Green Blue beams Increases significantly when you increase the light of the sun and at the beginning of the down fall at moment of sunrise.

- $\quad$ For reign Red in the red space in image ,Table.2,as we know the red reign it is space have (RGB) (red ,green ,blue) band but the red band is greater. The change is depending on light of sun. We can see different in the result between image $1 \& 2$ it is so bigger because in is the time of the sun risen

- For reign green in the green space in image, Table 3 ,as we know the green reign it is space have (RGB) (red ,green ,blue) band but the Green band is greater. The change is depending on light of sun. So the different in the result between image $1 \& 2$ it is so bigger because in is the time of the sun risen (but 
less then red bend) that means the san is effect on red band more then green

- For reign blue in the blue space in image, Table .4 ,as we know the blue reign it is space have (RGB) (red ,green ,blue) band but the blue band is greater. The change is depending on light of sun. So the different in the result between image $1 \& 2$ it is so bigger because in is the time of the sun risen (but less then red bend and more than blue) that means the san is effect on red band more than green $\&$ blue

- The Fig.9, we can see the reflection of different wave length (400, 428, $438,461,476,514,552,590.628,666,704$, and 742) $\mathrm{nm}$, for one line in image $1 \& 9$. The image one is les resolution from image 9 because the light of sun in les then (Moment Sunrise) for all wave length. But the image 9 is great then.

- For three reign (RGB) space in image taken in different wave like $254 \& 366$. We can fine no different in the sum reign but there is different anther, that is meaning when we use one wave length to take image, this image still have the variant of probates of (RGB colure) .the Fig.12, we can see the histogram and the different between image properties

- It is noted the existence of the difference clear in histogram between the original of images taken at different times and the histogram of images after improvement mean filter .see the Fig.4\&6, With note The disappearance of some packages in times of colorimetric and its appearance at other times based on the intensity and angle of light Source.

\section{CONCLUSION}

a. Some of bund color disappear when the intensity and angle of light fall change on the picture.

b. We can get the information for a color picture despite the use of a single wavelength of Photography because of the Image Save Information of reign (Red ,Green, Blue)

\section{REFERENCES}

[1]GUPTA.G,"Algorithm for Image Processing Using Improved Median Filter and Comparison of Mean, Median and Improved Median Filter", International Journal of Soft Computing and Engineering (IJSCE).2231-2307. November 2011.

[2]Chatterjee, P.,Joshi,N., and, Matsushita, Y, "Noise Suppression in Low-light Images through Joint Denoising and Demosaicing”. Univ. of California, Santa Cruz. 2010

[3]Debevec,P,'Image-Based Lighting" IEEE Computer Graphics and Applications .2001,in press

[4]Wetzstein1,G.,and, Heidrich1,W, and Luebke2, D,“ Optical Image Processing Using Light Modulation Displays" The University of British Columbia,in2009.

[5]Cewulu ,L.,Jiaya Jia,Y.,” Smoothing via L0 Gradient Minimization", ACM Transactions on Graphics, Vol. 30, No. 6, Article 174, The Chinese University of Hong Kong,December 2011.

[6]Abid,A., and Asal,A,'Hit Noise Reduction in some X-ray Images". Univ. of AL-Mustansiriya, College of Science, 2010

[7]CAMAG,C ,"Instrumental Thin-Layer Chromatography" .TLC E 996.2375-2 .2013. 